\title{
RESOLUÇÃO DE PROBLEMAS ENVOLVENDO POLÍGONOS REGULARES POR MEIO DO SCRATCH: UMA EXPERIÊNCIA NO ENSINO FUNDAMENTAL
}

\author{
Greice Borges Quequi - PPGEMat/UFRGS - greice.bquequi@ gmail.com - 0000-0001- \\ 9330-0122
}

Leandra Anversa Fioreze - PPGEMat/UFRGS - leandra.fioreze@ gmail.com - 0000-00026750-1497

\begin{abstract}
Resumo
O presente artigo tem como objetivo mostrar aspectos declarativos externalizados por estudantes do nono ano do Ensino Fundamental ao programar situações relacionadas à geometria dos polígonos regulares, por meio do software Scratch. O aporte teórico relacionado à compreensão do processo de construção dos conceitos baseia-se na Teoria dos Campos Conceituais, de Vergnaud, e o processo de programar e aprender é fundamentado no Construcionismo, de Seymour Papert. A experimentação foi realizada com discentes do nono ano do Ensino Fundamental dos Anos Finais de uma escola privada de Porto Alegre. A partir dos resultados, constatou-se que a externalização pelos estudantes de ações, ideias e registros escritos associada à programação com o software Scratch contribuiu para a resolução de situações relacionadas à geometria de polígonos regulares. O uso do Scratch foi relevante como ferramenta para pensar, construir e testar os teoremas em ação e os conceitos em ação dos estudantes.
\end{abstract}

Palavras-chave: Programação no Scratch; Polígonos Regulares; Ensino Fundamental; Teoria dos Campos Conceituais.

\section{TROUBLESHOOTING INVOLVING REGULAR POLYGONS THROUGH SCRATCH: AN EXPERIENCE IN ELEMENTARY EDUCATION}

\section{Summary}

This article aims to show declarative aspects externalized by students in the ninth year of elementary school, when programming situations related to the geometry of regular polygons, using the Scratch software. The theoretical contribution related to the understanding of the concept construction process is based on Vergnaud's Theory of Conceptual Fields and the programming and learning process is based on Seymour Papert's Constructionism. The experimentation was carried out with students from the ninth year of Elementary School of the Final Years of a private school of Porto Alegre. From the results, it was found that the externalization by students of actions, ideas and written records related to programming with the Scratch software contributed to the resolution of situations related to the geometry of regular polygons. The use of Scratch was relevant as a tool to think, build and test the theorems in action and the students' concepts in action.

Keywords: Scratch programming; Regular Polygons; Elementary School; Theory of Conceptual Fields. 


\section{Introdução}

Este artigo é resultado de uma pesquisa de dissertação de mestrado, que relaciona geometria plana à programação. Construímos situações escolares práticas que envolvem a programação objetivando entender como ocorre a aprendizagem dos estudantes de uma turma de $9^{\circ}$ ano em um colégio da rede privada de Porto Alegre. Mais especificamente, a pesquisa tem como objetivo geral investigar aspectos declarativos externalizados por estudantes do nono ano do Ensino Fundamental ao programar a resolução de situações-problema da Geometria de polígonos regulares, por meio do software Scratch.

O processo de programar e aprender baseia-se no Construcionismo, de Seymour Papert (1985, 1994). O software escolhido foi o Scratch, pois apresenta potencial para programar construções e animações que podem mobilizar o aprendizado de forma instigante, proporcionando aos estudantes a oportunidade de solucionar desafios e problemas. Como aporte teórico, a Teoria dos Campos Conceituais, de Vergnaud (1993, 1996, 2008), que visa compreender como ocorre a construção dos conceitos matemáticos, foi utilizada. Na sequência, desenvolveu-se a metodologia da pesquisa, bem como a análise do percurso da aprendizagem dos esquemas desenvolvidos pelos estudantes. Por fim, são apresentadas as considerações finais, retomando o percurso da pesquisa e seus resultados.

\section{O Construcionismo}

Conforme Maltempi (2000), o Construcionismo é tanto uma teoria de aprendizagem quanto uma estratégia para a educação, baseado no construtivismo. O Construcionismo fundamenta-se na ideia de que o desenvolvimento cognitivo ocorre pela construção e reconstrução das estruturas mentais, de modo que o conhecimento não deve ser apenas transmitido, mas sim um processo ativo do aluno.

Na perspectiva de Papert (1985), é a criança quem deve programar o computador para adquirir um sentimento de domínio sobre a máquina, construindo algumas ideias mais profundas de Ciência, Matemática e Arte. O Construcionismo, afirma Papert (1994), é construído pelas tentativas e descobertas ao resolver um problema, para o conhecimento gerar mais conhecimentos.

\subsection{O software Scratch}

O software de programação Scratch tem o mesmo propósito do Logo, sendo criado em 2008, no Media Lab, do Instituto de Tecnologia de Massachusetts (MIT) (Camargo, Fortunato, 2018). O termo Scratch deriva da técnica de Scratching, utilizada por Disco-Jokeys do Hip Hop, que manipulam o disco de vinil para frente e para trás, distorcendo a música e elaborando misturas de forma criativa. Esse programa, segundo Vecchia (2012), é uma linguagem de programação visual que permite ao usuário construir suas próprias histórias, animações, jogos, simuladores, ambientes virtuais de aprendizagem, músicas e arte, proporcionando ao usuário expressar seu pensamento com a utilização de comandos.

O layout do software apresenta-se da seguinte forma: há blocos de comandos organizados por tipo e cor, traduzidos para o português, e a execução da programação acontece na mesma tela, facilitando a compreensão ao analisar o que o personagem executa. Os blocos para as construções dos objetos (movimento, aparência, som, caneta, controle, sensores, números e variáveis) estão no centro, sendo que suas estruturas se encaixam como se fossem peças de Lego. A parte da animação, à direita, é chamada de palco; os atores do palco executam as programações realizadas e o ator, que é apresentado como default, é um gato, chamado de Sprite. A região à esquerda é destinada aos comandos de programação, em que os blocos são arrastados para o centro e encaixam-se com o uso do mouse, conforme Figura 1. 
Figura 1 - Interface do Scratch.

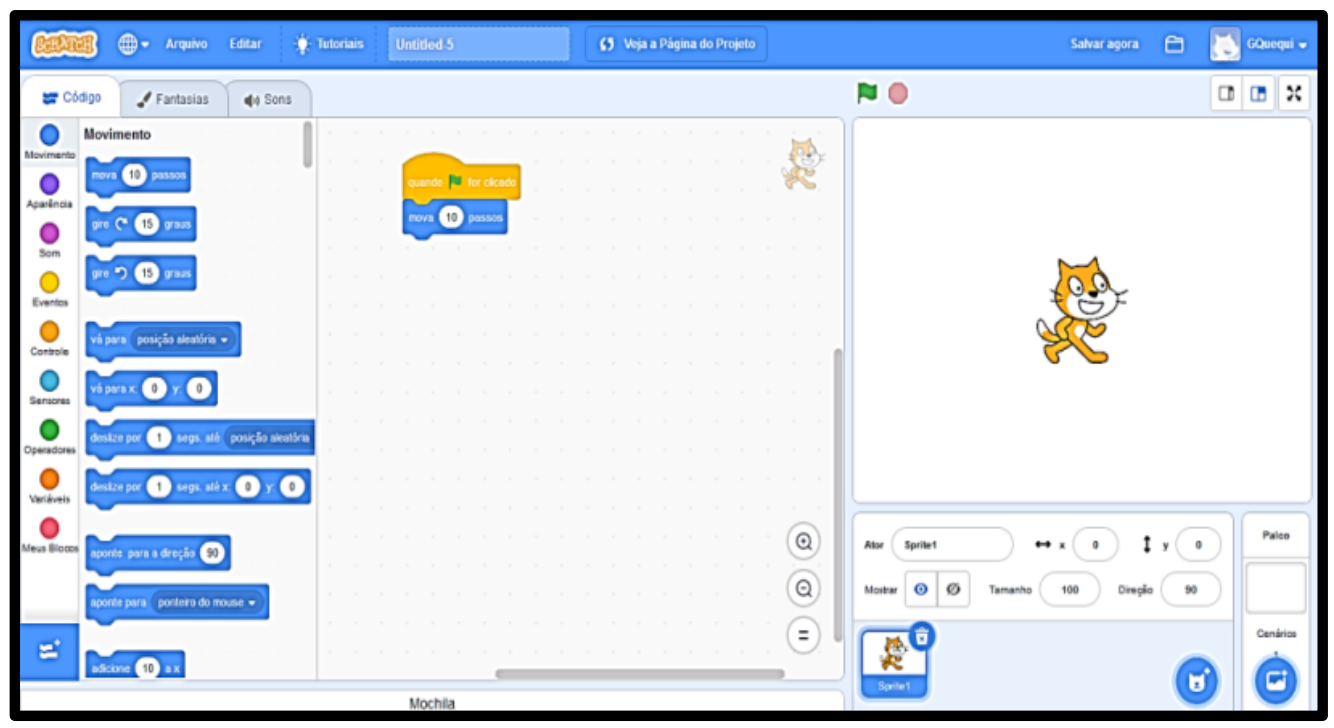

Fonte: Dados da pesquisa

O aluno tem acesso, à esquerda, a uma "caixa de ferramentas" em que ele escolhe qual ferramenta usar, sem necessitar escrever o comando, encaixando-a de acordo com uma determinada ordem lógica, o que facilita a construção da programação. Para mover-se no palco, construir um jogo, ou um projeto de seu interesse, o estudante necessita construir ou mobilizar seus conhecimentos matemáticos.

\section{A teoria dos Campos Conceituais}

A teoria dos Campos Conceituais foi elaborada "[...] para tentar melhor compreender os problemas de desenvolvimento específicos no interior de um mesmo campo de conhecimento" (VERGNAUD, 1996, p. 11). Dessa forma, o domínio do campo conceitual ocorre ao longo de um largo período de tempo através da experiência, maturidade e aprendizagem (Moreira, 2002).

Vergnaud (1996, p. 166) afirma que "uma abordagem psicológica e didática da formação de conceitos matemáticos conduz-nos a considerar o conceito um conjunto de invariantes utilizáveis na ação". Logo, é possível afirmar que a definição de um conceito seria o conjunto de situações que constituem a referência de suas propriedades e o conjunto de esquemas utilizados pelos sujeitos que fazem a construção de um campo conceitual. Cada conceito pode ser desenvolvido em variadas situações, e o professor deve analisar os inúmeros esquemas gerados pelos estudantes para solucionar o problema.

O conceito, segundo Vergnaud (1996), é uma trinca de conjuntos, C = (S, I, s). "S" é o conjunto das situações que dão sentido ao conceito (a referência); "I", o conjunto de invariantes nas quais assenta a operacionalidade dos esquemas (o significado); por fim, "s" é o conjunto das formas pertencentes e não pertencentes à linguagem que permitem representar simbolicamente o conceito, suas propriedades, as situações e os procedimentos de tratamento (o significante).

Uma situação é uma combinação de relações de base com dados conhecidos e desconhecidos, definida por Vergnaud (1993) como tarefa. Segundo Moreira (2002), toda a situação complexa pode ser analisada como uma combinação de tarefas. E, desse modo, são as situações "que dão sentido aos conceitos matemáticos" (VERGNAUD, 1996, p. 179).

O conceito de esquema é determinado pela organização invariante do comportamento do sujeito para uma classe de situações dadas (Vergnaud, 1993). São as formas de organização de um esquema que arranjam o pensamento, e é através dessas ações que o sujeito busca atingir 
um objetivo que é composto por invariantes operatórias (teoremas em ação e conceitos em ação) (Vergnaud, 1996). Nesse contexto, teorema em ação são proposições verdadeiras ou não sobre o real, e conceito em ação são objetos ou categorias de pensamento analisadas como relevantes. O termo "em ação" relaciona-se ao fato de que o estudante usa esses conhecimentos durante a resolução da situação (Rocha, Basso, 2017).

\section{Metodologia da pesquisa}

A metodologia de pesquisa é qualitativa, definida como aquela em que "a qualidade é do objeto e passível de ser observada" (BICUDO, 2012, p.17). Por esse viés, observa-se o sujeito para verificar seus comportamentos, de modo que seja possível interpretar os dados, sob a ótica de uma teoria que esteja relacionada com o que se está pesquisando (Bicudo, 2012).

A experimentação da pesquisa foi realizada em 2019, com vinte e oito discentes do nono ano do Ensino Fundamental dos Anos Finais de uma escola privada, localizada em Porto Alegre. Foram realizadas seis aulas de 100 minutos cada, que estão divididas entre atividades de programação no espaço físico e no software Scratch. Para a organização da pesquisa, sempre que um grupo de alunos foi referenciado (composto por trios), a identificação ocorreu por números, por exemplo, trio 1 , trio 2 , trio 3 . Em relação à coleta de dados, foram gravados áudios de todos os encontros, registros das produções dos alunos, fotos e programações dos estudantes no Scratch.

As atividades realizadas durante as aulas seguiram esta organização: 1) Introdução à linguagem de programação com o site "A hora do código: Programaê!"; 2) Realização de atividades envolvendo conceitos de Geometria e programação de forma desplugada (sem o uso do computador); 3) Apresentação do Scratch e de suas funcionalidades; 4) Construções de figuras planas pela programação no Scratch; 5) Desenvolvimento de um projeto com polígonos inscritos e circunscritos e 6) Construção da atividade final no Scratch.

Devido ao espaço deste artigo, as aulas 5 e 6 serão apresentadas com mais detalhes.

\section{Descrição e análise das aulas 5 e 6: programando e realizando construções geométricas}

$\mathrm{Na}$ aula 5, desenvolvida com a professora de Artes Visuais, os estudantes, separados em trios, planejaram um projeto envolvendo polígonos inscritos e circunscritos dispostos numa folha A3. Na aplicação da ideia, eles escolheram um polígono, realizaram a sua construção com régua e compasso e inscreveram nele uma circunferência ou outro polígono de sua escolha, formando sucessivamente construções de figuras planas que diminuem de tamanho proporcionalmente, representando a ideia de infinito. A última aula (aula 6) foi destinada à reprodução do desenho no Scratch de acordo com a construção realizada na atividade anterior, em que os estudantes poderiam escolher entre reproduzir o projeto já desenvolvido ou fazer sua adaptação para o Scratch. A fim de exemplificar a atividade, serão apresentadas as construções dos trios 3 e 11 .

$\mathrm{Na}$ construção com régua e compasso, o trio 3 partiu de uma circunferência inicial, usando o diâmetro máximo da folha $\mathrm{A} 3$, e construiu o primeiro triângulo equilátero, dividindo a sua circunferência em três partes iguais, marcando três pontos e unindo-os com segmentos de reta. Na sequência, repetiu-se o processo para formar outro triângulo equilátero, ficando cada um virado de cabeça para baixo do outro, com o aspecto de uma estrela. $\mathrm{O}$ trio repetiu o processo construindo outra circunferência inscrita ao desenho dos triângulos e assim sucessivamente. 
Figura 2 - Desenho do trio 3 de triângulos inscritos na circunferência.

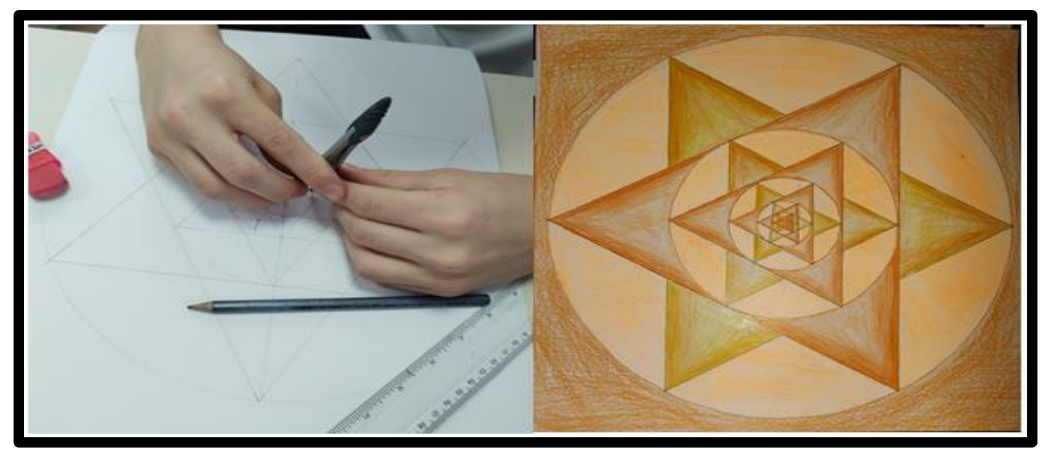

Fonte: Dados da pesquisa.

Ao realizar as construções geométricas com régua e compasso, os estudantes reconheceram as figuras utilizadas (triângulos equiláteros e círculos) quando expressaram matematicamente o pensamento na elaboração do desenho (Figura 2). Na construção, os estudantes precisaram saber a definição de triângulo equilátero, além de dividir a circunferência em partes iguais e trabalhar com inscrição e circunscrição de figuras. O desenvolvimento dessa atividade representou uma antecipação do projeto final construído no Scratch e proporcionou aos estudantes desenvolver diferentes formas de representar os polígonos regulares (no papel e no Scratch).

Vale destacar que o trio 3 não seguiu seu projeto original, em formato de estrela, feito no papel, e construiu uma sequência de triângulos equiláteros inscritos com os vértices do triângulo menor posicionados nos pontos médios dos lados do triângulo maior. Ao desenvolver a ideia e adaptá-la, os estudantes ensinaram a máquina a programar o projeto através do mundo do Scratch, tal como preconiza Papert (1985), testando e chegando às suas conclusões (Figura $3)$.

Figura 3 - Desenho no palco e programação do trio 3 referente a triângulos inscritos a outro triângulo.

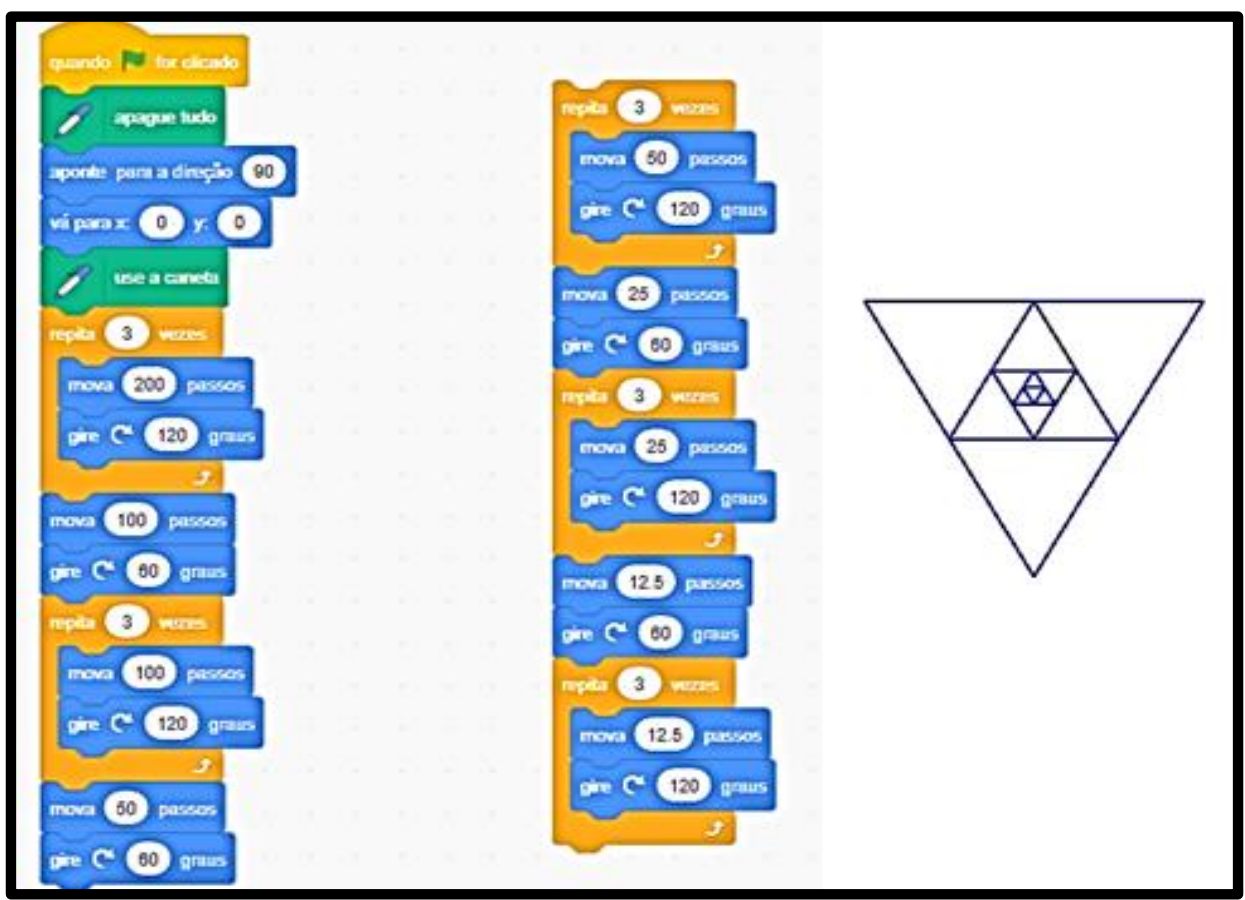

Fonte: Dados da pesquisa. 
Os estudantes do trio 3 fizeram, primeiramente, no papel, um esboço da construção dos triângulos equiláteros e perceberam a proporção entre as medidas dos lados, ou seja, a partir do triângulo maior, a sequência de triângulos inscritos possui a metade da medida do lado. $\mathrm{Na}$ sequência, eles construíram um algoritmo para programar no Scratch, relacionando a Geometria euclidiana com lápis e papel à Geometria do software. Os conceitos em ação mobilizados foram os seguintes: propriedades do triângulo equilátero, razão e proporção e ângulos internos e externos dos polígonos. Porém, os estudantes do trio 3 não perceberam uma repetição de processos utilizada na construção, ou seja, eles não sistematizaram, através do software, o comando "sempre", apenas repetiram o processo muitas vezes.

Os estudantes do trio 11 construíram um quadrado inscrito a uma circunferência com diâmetro máximo da folha $\mathrm{A} 3$. Na sequência, desenharam a reta mediatriz em relação ao diâmetro, que passa no centro da circunferência, dividindo-a em quatro partes iguais. Nos pontos de intersecção da reta com a circunferência, desenharam o quadrado. Tomando como base essa construção, delinearam outra circunferência inscrita a este quadrado, com o raio sendo a metade da medida do lado. Os pontos de intersecção entre esta nova circunferência e o quadrado formaram outro quadrado proporcionalmente menor que está rotacionado 45 graus ao anterior e assim sucessivamente. Segue o projeto do trio 11, conforme Figura 4.

Figura 4 - Desenho de quadrados inscritos na circunferência do trio 11.

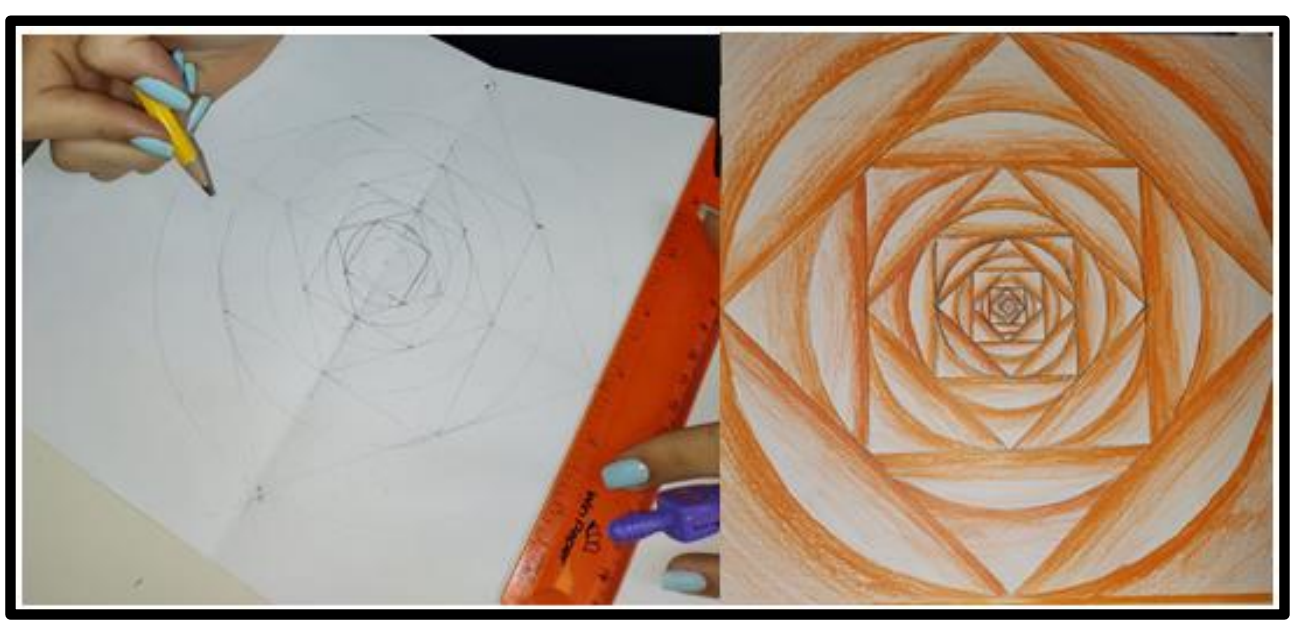

Fonte: Dados da pesquisa.

O trio 11 foi o único que utilizou a razão de proporção, relacionando-a com a circunferência e com o lado do quadrado como variável. Os estudantes empregaram o comando "sempre" para que o processo se repetisse com o valor da razão entre as medidas dos lados dos quadrados, formando assim um desenho semelhante a um fractal. Na Figura 5, temos o desenho no palco e a programação das figuras inscritas e circunscritas. 
Figura 5 - Desenho no palco e programação do trio 11.

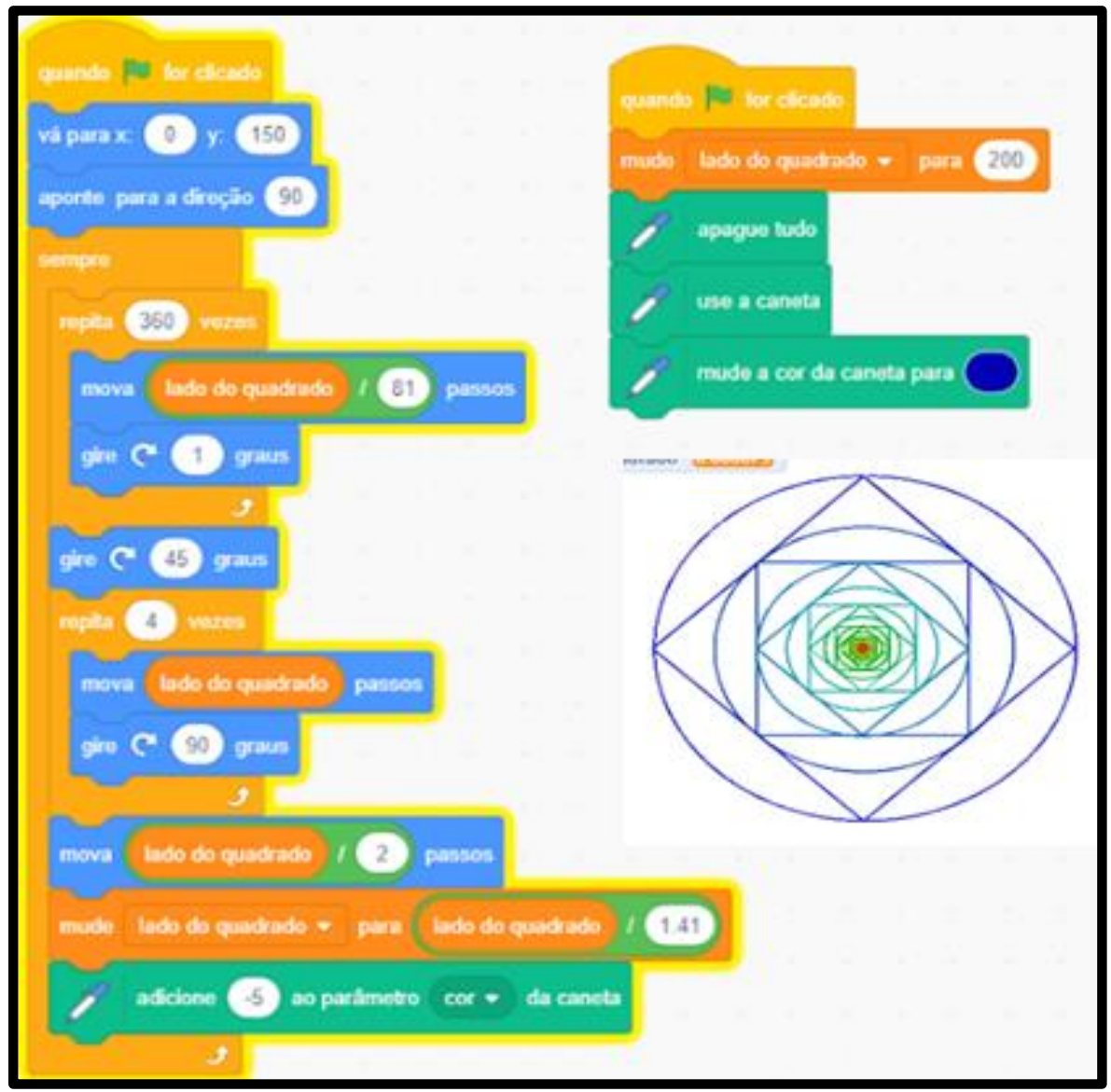

Fonte: Dados da pesquisa.

Esse trio percebeu uma relação entre as medidas dos lados da figura e, diferente dos outros, padronizou a relação encontrada ao programar, utilizando o comando "sempre". O desenho no papel e no Scratch assemelham-se a um fractal, porém a iteração é finita. Na programação, ocorre uma pausa, o que não acontece com um fractal de fato. Segundo Vergnaud (1993), os estudantes, ao resolverem o problema e utilizarem o comando "sempre", buscaram a solução ao observar padrões que se repetem na construção fazendo o uso de esquemas conhecidos. Assim, a partir de algumas avaliações prévias, alteraram a programação, descobrindo outros aspectos ou, até mesmo, novos esquemas. Com o tempo, esses esquemas tornam-se automatizados e indicam possíveis compreensões e relações estabelecidas pelos estudantes.

Vergnaud (1990) afirma que as situações em que os alunos não dispõem de todas as competências necessárias, conduzindo a um tempo de reflexão e exploração, de metas e antecipações, de regras para as ações e de utilização de invariantes operatórios são ingredientes importantes para a construção dos esquemas que constituem a base conceitual. Conseguimos perceber, durante a programação do Scratch, metas (desenho com sensação de infinito originado na construção com régua e compasso), antecipações através dos esquemas no papel e das regras e padronizações para as ações do Sprite no palco durante a construção do desenho.

\section{Considerações Finais}

Ao longo das atividades, buscou-se investigar aspectos declarativos externalizados por estudantes do nono ano do Ensino Fundamental ao programarem a resolução de situações RENOTE 
problema da Geometria de polígonos regulares, por meio do software Scratch. Compreender essa questão exige um olhar para o estudante em questão, levando-o não somente a analisar a sua programação, mas também o seu produto final.

Ao analisar as programações criadas pelos alunos, identifica-se que eles conseguiram criar articulação com os conhecimentos de Geometria que foram mobilizados nas resoluções de situações-problema. Os estudantes demonstraram ter conhecimentos prévios sobre as propriedades euclidianas das figuras e ampliaram essas informações durante a pesquisa, incorporando-as nas programações. O conjunto diversificado de situações envolvendo programação e Geometria possibilitou que os alunos desenvolvessem esquemas e utilizassem diferentes representações, construindo conceitos geométricos, principalmente de polígonos regulares (Vergnaud, 1993). Também foi perceptível que os participantes da pesquisa externalizaram conhecimentos, ideias, suposições e registros escritos através da resolução das situações; sistematizaram mecanismos de resolução, formando algoritmos, desenvolvendo o seu pensamento e expressando suas ideias de diferentes formas na construção com régua e compasso e na linguagem de programação.

$\mathrm{Na}$ análise de dados relacionadas às construções dos projetos, envolvendo polígonos inscritos e circunscritos, percebemos que os estudantes compreenderam as propriedades dos polígonos regulares, aprenderam a inscrever e circunscrever polígonos e circunferências, que envolveram o entendimento de ângulos e de medidas dos lados, além de mobilizar conceitos de razão e proporção. Consideramos que os estudantes aprenderam diversos conceitos geométricos através da programação para a construção dos projetos dos trios e que o uso do Scratch foi relevante como ferramenta para pensar, construir e testar seus teoremas em ação e seus conceitos em ação. Além disso, "a teoria dos campos conceituais se mostrou adequada para analisar as construções conceituais em que o sujeito é ativo" (FIOREZE et al, 2013, p. 276), principalmente em seu processo de aprender; tal característica se relaciona com $o$ Construcionismo, destacando o processo de autoria na construção dos projetos dos trios.

O trabalho desenvolvido nos fez refletir sobre o ensino de Geometria nos Anos Finais: a partir da diversidade de situações, o professor pode possibilitar a ampliação do entendimento de propriedades e de esquemas que os alunos podem mobilizar e, desse modo, a programação mostrou-se aliada neste processo. Assim, dominar um campo conceitual consiste em resolver uma diversidade de problemas em que os conceitos se inserem (Vergnaud, 2008). Também nos fez refletir sobre nossas práticas enquanto professor e pesquisador; muitas vezes o professor é o orientador no processo, ou mesmo aprendiz, compreendendo que a programação pode ser uma aliada para o desenvolvimento da aprendizagem da Matemática.

\section{Referências}

BICUDO, M. A. V. A pesquisa em educação matemática: a prevalência da abordagem qualitativa. Revista Brasileira de Ensino de Ciências e Tecnologia. Curitiba, v. 5, n. 2, mai./ago. 2012.

CAMARGO, I.; FOTUNATO, I. O Scratch como auxiliar no processo de ensino-aprendizagem de linguagem de programação: um balanço da pós-graduação nacional entre 2010 e 2016. RPGE - Revista online de Política e Gestão Educacional, Araraquara, v. 22, n. 2, p. 608626. 2018. Disponível em: https://periodicos.fclar.unesp.br/rpge/article/view/10754. Acesso em: 31 de out. 2021.

FIOREZE, L. A. et al. Análise da construção dos conceitos de proporcionalidade com a utilização do software geoplano virtual. Ciência \& Educação, Bauru, v. 19, n. 2, p. 267-278, 2013 
MALTEMPI, M.V. O Computador em Sala de Aula: Articulando Saberes. Internet. In: F.M.P. Freire e M.E.B.B. Prado, Campinas, UNICAMP/NIED. p. 229-263. 2000.

MOREIRA, M. A. A Teoria dos Campos Conceituais de Vergnaud, o ensino de ciências e a pesquisa nesta área. Investigações em Ensino de Ciências. v. 7, p. 7-29, 2002.

PAPERT, S. Logo: computadores e educação. Tradução de Jose A. Valente, Beatriz Bitelman e Afira V. Ripper. Editora Brasiliense, São Paulo. 1985. 256 p.

PAPERT, S. A máquina das crianças: repensando a escola na era da Informática. Porto Alegre: Artes Médicas, 1994. 210 p.

ROCHA, K. C. Teoria dos Campos Conceituais na análise de programação em Scratch. Revista Novas Tecnologias na Educação, Porto Alegre. v. 15 n. 2, 2017.

VECCHIA, R. D. A modelagem matemática e a realidade do mundo cibernético. 2012. 275 p. Tese (Doutorado em Educação Matemática) - Instituto de Geociências e Ciências Exatas, Universidade Estadual Paulista, Rio Claro, 2012.

VERGNAUD, G. La théorie des champs conceptuels. Recherches em Didactiques des Mathématiques. v. 10, p. 133-170, 1990.

VERGNAUD, G. Teoria dos campos conceituais. Seminário internacional de educação matemática do Rio de Janeiro, Rio de Janeiro, p. 1-26. 1993.

VERGNAUD, G. Teoria dos Campos Conceptuais. In: BRUN, Jean. Didáctica das Matemáticas. Lisboa: Instituto Piaget. Horizontes Pedagógicos, p.155-191. 1996.

VERGNAUD, G. Atividade humana e conceituação. Porto Alegre: GEEMPA, 2008. 